\title{
EMPREENDIMENTOS ECÔNOMICOS SOLIDÁRIOS COMO ALTERNATIVAS DE DESENVOLVIMENTO: MAPEAMENTO DE AÇÕES PRESENTES NO MÉDIO SERTÃO PARAIBANO
}

\author{
Eunice Ferreira Carvalho ${ }^{1}$ \\ Francisca dos Santos Lopes ${ }^{2}$ \\ Cícera Roberta Mendes dos Santos ${ }^{3}$ \\ Thays Santana dos Santos Nascimento ${ }^{4}$ \\ Lucas Andrade de Morais ${ }^{5}$
}

RESUMO Diante as muitas transformações do sistema capitalista produtivo, ocasionados pela crescente demanda do consumo, tem-se que a Economia Solidária vem se confirmando nas últimas décadas como importante caminho para mudança econômica e social pelo mundo. Nisso, o presente estudo voltou-se a mapear os empreendimentos econômicos solidários existentes, de modo particular na região do médio Sertão paraibano brasileiro, analisar os benefícios destes para as comunidades locais e para o seu desenvolvimento, bem como identificar os incentivos da gestão pública municipal/estadual voltados ao fomento desses EES. Para tanto, adotou-se a pesquisa qualitativa descritiva, documental e de estudo de campo, onde foram analisados dados da região do Sertão e observados empreendimentos localizados nessa área. O resultado demonstrou que, a região apresenta uma diversidade de atividades econômicas solidárias, espalhadas pelas várias cidades que a compõem, sendo que estes empreendimentos se configuram como importante fonte de renda e inclusão social, e que falta o apoio dos gestores públicos para ajudar a solucionar os desafios impostos a esses empreendedores. Conclui-se, portanto, que a Economia Solidária juntamente com seus empreendimentos solidários e empreendedores envolvidos, embora esteja tendo maior visibilidade na atualidade, e se confirmando como caminho para o desenvolvimento local, ainda necessita de incentivos de políticas públicas, para que de fato se constitua como meio viável de produção, e contribuía de modo ainda mais expressivo para a construção de uma sociedade justa e solidária.

Palavras-chave: Mapeamento, Empreendimentos Solidários, Sertão paraibano.

ABSTRACT: In view of the many transformations in the productive capitalist system, caused by the growing demand for consumption, the Solidarity Economy has been confirmed in recent decades as an important path for economic and social change around the world. In this context, the present study returned to map the existing solidary economic enterprises, particularly in the region of the Brazilian middle Sertão, to analyze the benefits of these for the local communities and for their

\footnotetext{
${ }^{1}$ Economista e professora (UEPB/Campus VII). E-mail: elocarvalho12@gamil.com

${ }^{2}$ Aluna do curso de Administração (UEPB/Campus VII). E-mail: nenninhasantos@gmail.com

${ }^{3}$ Aluna do curso de Administração (UEPB/Campus VII). E-mail: cicerarobertamendes@gmail.com

${ }^{4}$ Aluna do curso de Administração (UEPB /Campus VII) E-mail: thayssantanasn@gmail.com

${ }^{5}$ Administrador e professor (UEPB - Campus -VII) E-mail: lucasmorais7@gamil.com
} 
development, as well as to identify the incentives of the municipal public management. / state focused on promoting these EES. To this end, qualitative descriptive, documentary and field study research was adopted, where data from the Sertão region were analyzed and developments located in this area were observed. The result showed that the region has a diversity of solidary economic activities, spread over the various cities that compose it, and these enterprises are configured as an important source of income and social inclusion, and that the support of public managers is lacking to help solve the challenges imposed on these entrepreneurs. It is concluded, therefore, that the Solidarity Economy together with its solidarity ventures and involved entrepreneurs, although it is having greater visibility nowadays, and confirming itself as a path for local development, still needs public policy incentives, so that in fact it constitutes a viable means of production, and contributed even more significantly to the construction of a just and solidary society.

Keywords: Mapping, Solidarity Enterprises, Sertão paraibano

\section{INTRODUÇÃO}

A organização da sociedade, da produção e do consumo assumiu historicamente, valores patriarcais e patrimonialistas, responsáveis por sustentar relações de poder entre os indivíduos. Nesse contexto, as garantias sociais são divididas de forma desigual, estratificando a sociedade em classes mais e menos privilegiadas, de modo a estabelecer um ambiente de pouca coesão social, uma vez que os laços de solidariedade entre os indivíduos são reiteradamente fragilizados.

As transformações do sistema produtivo e a interligação dos mercados num ritmo mais acelerado, inerente ao capitalismo, têm uma manifestação territorial clara e sabemos que o Brasil é um exemplo clássico de uma sociedade capitalista de desenvolvimento marcadamente desigual, o que se agrava com as enormes dimensões territoriais do país.

Nesse contexto, a agricultura assumiu um papel secundário de fornecedora de matéria prima e capital para a indústria nacional. Passou então a predominar na política brasileira, uma teoria urbana para o desenvolvimento rural que implicou na modernização da agricultura ${ }^{6}$. Essa estratégia, porém, levou ao fortalecimento das elites rurais e urbanas por intermédio de financiamentos e incentivos que possibilitaram a utilização de mecanização poupadora de mão de obra no campo ao mesmo tempo em que fomentaram a crescente indústria de insumos agrícola. Essa

\footnotetext{
6 "Modernização do latifúndio e criação de grandes e médias empresas de insumos agrícolas, como alternativa à reforma agrária, deixando à margem desse processo os agricultores familiares" (COSTA, 2015).
} 
escolha foi responsável ainda, segundo Costa (2015), por acentuados danos ecológicos e sociais.

O Semiárido brasileiro, por exemplo, possui uma grande extensão territorial e, historicamente, sempre esteve nas mãos de uma pequena elite de latifundiários. Esse cenário causou exclusão econômica e social contribuindo para que cerca de 1,5 milhão de famílias agricultoras $(28,82 \%$ de toda a agricultura familiar brasileira) ocupassem apenas 4,2\% das terras agricultáveis do Semiárido (IBGE, 2010). A concentração de terras, de renda, o aumento da pobreza, do desemprego e etc., são indicadores que requerem políticas públicas voltadas, efetivamente, no sentido de melhorar as condições de vida da população principalmente do ponto de vista local.

Quanto ao desenvolvimento da agricultura familiar, depende da formulação de políticas voltadas para apoiar, consolidar e expandir essa produção. No entanto, a intervenção do Estado foi sempre marcada, principalmente no Nordeste, pela centralização e fragmentação das ações, e se solidificava com a criação de órgãos nacionais para o combate à seca, os quais se transformavam em objeto de disputas políticas entre os vários segmentos da elite rural. Em suma, afirma-se que as políticas de desenvolvimento regional adotadas no Brasil a partir dos anos sessenta, que foram baseadas nos incentivos fiscais e financeiros e dirigidas exclusivamente pelo Estado, não conseguiram estimular o desenvolvimento sustentado com base na mobilização dos recursos locais.

No intuito de superar esses resultados insatisfatórios começaram a ser desenvolvidas outras alternativas no campo das políticas com a finalidade de a competitividade por meio da mobilização do potencial endógeno das áreas menos desenvolvidas.

Anseia-se assim, que a sustentabilidade local seja alinhada com as vocações, especialidades e potencialidades que a região possui. Esse alinhamento é importante para que os atores articulem e formulem estratégias que realmente contribuam com o desenvolvimento local principalmente com a elaboração de política públicas que tenham como foco a sustentabilidade da região. 
Esse contexto chama a atenção para a perspectiva de que a Economia Solidária ${ }^{7}$ apresenta-se como uma alternativa para enfrentar os problemas da economia regional, sobretudo, à exclusão dos trabalhadores do processo de produção nos moldes da economia capitalista.

A economia solidária propõe enfim, a livre mobilização para o trabalho e geração de renda, a partir do fortalecimento econômico, social e ambiental das comunidades, uma vez que percebe a formação de relações produtivas mais justas, sustentáveis e não hierarquizadas, como um caminho viável para o desenvolvimento.

No Brasil, a atuação dos governos com ações e programas de apoio à Economia Solidária configura uma experimentação importante na construção da política pública da Economia Solidária. Essas políticas obtiveram destaque com a criação da Secretaria Nacional de Economia Solidária pelo governo federal, no ano de 2003. Considera-se, portanto, que a Economia Solidária está, de forma crescente, sendo incorporada à agenda pública (Schiochet,2012).

A mesorregião do sertão paraibano por apresentar uma realidade peculiar, onde a situação de escassez hídrica tem atingido muitas famílias, pode evidenciar a importância do desenvolvimento da Economia Solidária, como estratégia de sobrevivência a partir da produção cooperada que respeita a capacidade de resiliência dos recursos naturais bem como na participação paritária dos envolvidos, tanto da produção quanto dos destinos das riquezas coletivamente produzidas. Neste sentido é que, em 2014, foi criado o Plano Estadual de Economia Solidária, pelo governo do Estado da Paraíba com o objetivo de orientar na formulação de ações e projetos que visam o fortalecimento, ampliação e aperfeiçoamento da Economia Solidária do Estado da Paraíba, como alternativa de desenvolvimento ao modelo vigente, na perspectiva de inclusão social. Portanto, o objetivo geral desta pesquisa é evidenciar os empreendimentos econômicos solidários na região do Sertão sob a ótica do desenvolvimento local. Para tanto, será mapeado os principais empreendimentos de Economia Solidária existentes na região, mostrando o perfil econômico desses empreendimentos bem como as ações do Poder Público

\footnotetext{
${ }^{7}$ A Economia Solidária possui uma finalidade multidimensional, isto é, envolve a dimensão social, econômica, política, ecológica e cultural, ou seja, reafirma a emergência da emancipação de trabalhadores como sujeitos históricos a partir de preceitos como solidariedade, autogestão, cooperativismo, confiança e equidade. (Ramalho et. All., 2014).
} 
Estadual/municipal a essa atividade, destacando, sobretudo a importância de Economia Solidária para a região e os seus principais desafios.

\section{EMBASAMENTO TEÓRICO}

\subsection{A ECONOMIA SOLIDÁRIA E SEUS PRINCÍPIOS NORTEADORES}

Como alternativa para as crises que emergiam pós Revolução Industrial, e que intensificaram as desigualdades sociais, surge a chamada Economia Solidária que busca, sobretudo, produzir com igualdade, baseado na tomada de decisão democrática e com participação ativa de todos os seus membros. Singer (2002, p.10) define Economia Solidária como sendo: "[...] outro modo de produção, cujos princípios básicos são a propriedade coletiva ou associada do capital e o direito à liberdade individual". Portanto, para que se constitua uma sociedade mais justa e igualitária é fundamental que os participantes atuem na atividade econômica de forma cooperada. (SINGER, 2002). Esta se baseia nos princípios da Autogestão, da Democracia, da Cooperação e da Solidariedade.

A autogestão é a maneira como os empreendimentos solidários são administrados, contrapondo-se a administração por meio da heterogestão das empresas capitalistas. Para Singer (2002, p.16) esta "talvez seja a principal diferença entre a economia capitalista e solidária". No Capitalismo e no seu modo de administra-se, os indivíduos trabalham isoladamente para receber um salário préestabelecido pelos detentores do capital. Estes não participam das decisões que os afetam, nem tampouco detém o conhecimento de todas as etapas acerca daquilo que produzem. O sistema atua de forma hierarquizada, onde as ordens surgem num processo de cima para baixo, o que pode gerar alta competitividade até mesmo dentro da organização, e entre seus membros.

Já na Economia Solidária todos participam de todas as etapas. Singer (2002, p.18) afirma que "a empresa solidária se administra democraticamente, ou seja, pratica a autogestão.”. Albuquerque (2003, p. 20) define a autogestão como:

[...] conjunto de práticas sociais que se caracteriza pela natureza democrática das tomadas de decisão, que propicia a autonomia de um "coletivo". É um exercício de poder compartilhado, que qualifica as relações sociais de cooperação entre pessoas e/ou grupos, independente do tipo das 
estruturas organizativas ou das atividades, por expressarem intencionalmente relações sociais mais horizontais.

Nota-se, portanto, que nos empreendimentos solidários a autogestão é uma característica essencial, onde se possam promover ações em prol da coletividade. Diferentemente do que se tem na heterogestão, na autogestão as ordens partem do nível mais baixo para o mais alto, onde a maior autoridade é constituída de uma assembleia geral formada por todos os sócios, bem como as decisões são tomadas por todos, onde cada indivíduo tem direito a um voto, o que evidencia o princípio da democracia. Os ganhos são divididos entre todos os membros, podendo existir uma pequena diferença aceitável, a depender da função exercida pelo indivíduo, e desde que essas tarefas que são mais bem recompensadas gerem ganhos para todos.

A cooperação e a solidariedade também estão presentes no dia-a-dia dos empreendimentos solidários. Singer (2002, p.9-10) afirma que " a solidariedade na economia só pode se realizar se ela for organizada igualitariamente pelos os que se associam para produzir, comercializar, consumir ou poupar. A chave dessa proposta é a associação entre iguais em vez do contrato entre desiguais".

A solidariedade pauta-se então, na igualdade entre os membros, que se unem para produzir bens ou serviços. Estes têm características em comum e buscam juntos objetivos coletivos por meio da cooperação: se há ganhos, estes são de todos; se há prejuízos, todos os assumem.

A Economia Solidária quer promover, portanto, a inclusão de todos, garantindo-Ihes renda para seus sustentos, e ainda mais, a dignidade. A autogestão evidenciada nos empreendimentos solidários almeja desenvolver o ser humano, e o surgimento de organizações solidárias é um meio de difundir pelo mundo a ideia de que é possível desenvolver as atividades econômicas de forma democrática e igualitária. (SINGER, 2002). No Brasil e nas suas diversas regiões, os EES (Empreendimentos Econômicos Solidários) também começam a surgir como uma resposta das classes mais baixas aos seus precários meios de vida.

\subsection{ORIGEM HISTÓRICA DA ECONOMIA SOLIDÁRIA (BRASIL E PARAÍBA)}

A competitividade imposta pelo sistema capitalista sempre gerou desigualdades sociais, por meio da divisão entre os que detêm o capital e os 
detentores da força de trabalho. Essa separação leva a formação de pequenos grupos de ganhadores que acumulam vantagens, e a polarização da grande massa dos que se tornam perdedores, acumulando desvantagens presentes e futuras. (SINGER, 2002).

Tem-se então que, foi a partir da Revolução Industrial e do surgimento de maquinarias, que impactou fortemente a classe de trabalhadores operários, por meio da substituição da sua mão-de-obra pela máquina, que as desigualdades sociais intensificaram-se. Muitos trabalhadores perderem seus postos de trabalho, o que levou a um alto índice de desemprego e miserabilidade. Singer (2002, p.24) confirma que: "A economia solidária nasceu pouco depois do capitalismo industrial, como reação ao espantoso empobrecimento dos artesãos provocado pela difusão das máquinas e da organização fabril da produção". Foi então neste cenário de contradições do Capitalismo que nasceram às oportunidades de criação de organizações solidárias, cuja lógica é produzir de modo contrário ao sistema dominante. (PINHEIRO, 2013).

A precarização de vida de muitos operários fez com que surgissem pessoas em defesa da classe, propondo, por exemplo, leis trabalhistas que viessem dá garantias aos trabalhadores. Dentre essas pessoas estava Robert Owen, o britânico. Este foi o primeiro a propor a construção de Aldeias Cooperativistas, que pudessem abrigar os pobres que se constituíam de um número significativo. (SINGER, 2002)

A partir de então, difundiu-se pelo mundo a ideia de que a cooperação era um meio que poderia possibilitar ganhos a todos, principalmente aos mais necessitados. Observou-se que "[...] novos sindicatos foram formados e, juntamente com eles, cooperativas" (SINGER, 2002, p.27). As cooperativas surgiam principalmente como resposta dos trabalhadores para a defasagem da sua classe, imposta pelos empregadores. Segundo Cole (1944, p.24) apud Singer (2002, p.29) "Muitas das sociedades cooperativas que foram fundadas no fim dos anos 20 e começo dos 30 (do século XIX) eram desta espécie, originadas ou de greves ou diretamente de grupos locais de sindicalista, que haviam sofrido rebaixa de salários ou falta de empregos".

Essas primeiras iniciativas foram o espelho para que surgissem diversas outras cooperativas e sindicatos, até mesmo os chamados "clubes de trocas" que possibilitavam um comércio de compras e vendas de bens e serviços entre seus 
membros. A luta crescente dos trabalhadores contra o sistema capitalista e empregadores, alcançava seu auge no ano de 1833. Percebeu-se que tudo era possível de alcançar, desde que houvesse uma participação ativa de todos. (SINGER, 2002). Tem-se então que, a luta de classes desfavorecidas e oprimidas, que reuniram forças para buscar seu espaço na sociedade, deu origem a Economia Solidária.

Esta é a origem da economia solidária. Seria justo chamar esta fase inicial de sua história de "cooperativismo revolucionário", o qual jamais se repetiu de forma tão nítida. Ela tornou evidente a ligação essencial da economia solidária com a crítica operária e socialista capitalista. (SINGER, 2002, p.35)

Os movimentos solidários que surgiam eram mais do que um modo de produção para garantir trabalho e renda para os excluídos, sendo também uma forma de evidenciar a insatisfação da maioria daqueles que se vinham discriminados e explorados pelo capitalismo dominante. Ortiz (2011) aponta que a economia solidária envolve diversas formas de organizações, nas quais os cidadãos buscam a criação de fontes que os levem ao acesso de produtos e serviços com um menor custo e maior qualidade, sendo que os interesses coletivos e individuais são evidenciados por meio de uma relação recíproca e solidária.

No Brasil, esse novo modo de produção que se disseminava pelo mundo chegou em forma de cooperativismo em meados do século XX. Porém, foi após a crise vivenciada pelo país nas décadas de 1980 e 1990 que a Economia Solidária reviveu. Conforme Gomes (2005), o cooperativismo surgiu pela região Nordeste, onde se fortaleceu a partir do século XIX. O autor ainda aponta que este se constituiu em uma "possibilidade de organização social e de alternativa econômica dos trabalhadores brasileiros" (GOMES, 2005, p.19). Esta recebeu apoio de entidades religiosas, sobretudo, da Cáritas, entidade ligada a Conferência Nacional de Bispos Brasileiros (CNBB) (FERREIRA, 2000).

As ações que desenvolveram eram voltadas principalmente para integrar os pobres que tinham sido atingidos pela fase de crise no Brasil, época está em que se acentuou a exclusão social. Empresas que faliram ou estavam a ponto de fechar as portas eram tomadas pelos trabalhadores que reformulavam seu modo de administrar, ressurgindo assim, cooperativas autogestionárias. 
Muitos outros movimentos passaram a acontecer no contexto da Economia Solidária. Conforme Ferreira (2000) o MST (Movimento dos Trabalhadores Sem Terra), por exemplo, começou a promover a agricultura que se consolidava por meio de cooperativas que tinham por base a autogestão; entidades universitárias começaram a apoiar indivíduos que desejavam produzir em conjunto, oferecendoIhes capacitações, dentre outras contribuições. Tudo isso fez com que os movimentos e incentivos a nova economia se difundisse pelo país em suas diversas regiões.

No estado da Paraíba que se localiza na região do nordeste brasileiro, evidencia-se ao longo dos anos uma série de movimentos voltados para a Economia Solidária, o que fez surgir diversos empreendimentos. Dados da SIES (2009) apontavam que a Economia Solidária vinha se consolidando como um importante caminho para o desenvolvimento de atividades do tipo agricultura familiar, onde se visualizou cerca de 43 empreendimentos espalhados pelas diversas regiões do estado. (CRUZ, CAVALCANTI E PESSOA, 2018)

Mapeamentos mais recentes (ano de 2007 e 2013) mostraram que Empreendimentos Solidários enfrentam constantes desafios no estado, e que estes vêm sendo acompanhados desde o ano de 2003 pelo Fórum Estadual de Economia Solidária, que junto a outros envolvidos busca melhorias para esses empreendimentos (PLANO ESTADUAL DE ECONOMIA SOLIDÁRIA, 2017)

Notadamente, há uma evolução no campo da Economia Solidária no estado, aonde um conjunto de iniciativas vem gerando benefícios para os que desejam ser incluídos na sociedade com garantias mínimas de sobrevivência. Segundo o Plano de Economia Solidária do estado (2017), os empreendimentos solidários voltados para produção ou comercialização se destacam, e mesmo diante diversos dilemas enfrentados, os EES conseguem obter um rendimento econômico satisfatório. Portanto, tem-se que os empreendimentos solidários contribuem diretamente para o desenvolvimento local, uma vez que gera emprego e renda. Estes podem ter características distintas, porém buscam a mesma finalidade: promover o bem comum. 


\title{
2.3 AS CARACTERÍSTICAS COOPERATIVISTAS DA ECONOMIA SOLIDÁRIA
}

O movimento da Economia Solidária difundido pelo mundo teve como base o cooperativismo de consumo, sendo a chamada cooperativa dos Pioneiros Equitativos de Rochdale considerada a primogênita e mãe de todas as outras (SINGER, 2002). A partir desta, emergiu-se pelos diversos países modelos de cooperativismos: os de crédito, os de produção, os de compras e vendas, e os clubes de trocas. Os que ambos tinham em comum era o seu modo de produzir, comercializar e poupar, adotando-se uma série de princípios.

\begin{abstract}
Adotaram uma série de princípios, que seriam depois imortalizados como os princípios universais do cooperativismo: $1^{\circ}$ ) que nas decisões a serem tomadas cada membro teria direito a um voto, independentemente de quanto investiu na cooperativa; $\left.2^{\circ}\right)$ o número de membros da cooperativa era aberto, sendo em principio aceito quem desejasse aderir. Por isto este principio é conhecido como o da " porta aberta"; $3^{\circ}$ ) sobre capital emprestado a cooperativa pagaria uma taxa de juros fixa; $4^{\circ}$ ) as sobras seriam divididas entre os membros em proporção às compras de cada um na cooperativa; $\left.5^{\circ}\right)$ as vendas feitas pela cooperativa seriam sempre feitas à vista; $6^{\circ}$ ) os produtos vendidos pela cooperativa seriam sempre puros (isto é, não adulterados); $7^{\circ}$ ) a cooperativa se empenharia na educação cooperativa; $8^{\circ}$ ) a cooperativa manter-se-ia sempre neutra em questões religiosas e políticas (SINGER, 2002, p.39-40)
\end{abstract}

Todos esses elementos formulados fizeram com que se pudesse produzir e comercializar de maneira cooperada, onde se tinha uma relação de confiança e reciprocidade, evidenciando assim a Economia Solidária e seus princípios norteadores.

No que concerne ao cooperativismo de crédito este é considerado uma invenção alemã, sendo especialmente formados por grupos de poupadores que se juntam para fornecer acesso a crédito para aqueles que fazem parte do grupo, onde cada um tem seus deveres e direitos. (SINGER, 2002). Outro modelo de cooperativismo que se difundiu pelo mundo é o chamado cooperativismo de compras e vendas, que se baseiam na relação de compras e vendas de bens entre pessoas que buscam um ganho de escala, sendo formado geralmente por pequenos e médios produtores. (SINGER, 2002)

Já as Cooperativas de Produção são o protótipo de empresa solidária (SINGER, 2002), sendo que busca a associação direta dos produtores que desejam ofertar no mercado seus produtos. Nesse sentido, Singer (2002) afirma que a gestão pública é vista como importante fator para ajudar na propagação das cooperativas 
de produção, sendo que faltam recursos financeiros aos trabalhadores e há uma grande disputa de mercado, onde se concorre com empresas capitalistas que muitas vezes contam com ajuda do Estado, por meio de isenções e subsídios.

Os clubes de trocas, por sua vez, são uma invenção recente na Economia Solidária, sendo clubes formados com a intenção de promover encontros entre aqueles que têm algo a vender ou desejam comprar. (SINGER, 2002). Nessa relação, visualizam-se ganhos mútuos, tanto monetários como sociais, promovidos pela relação entre os membros.

Todos esses movimentos propostos pelas cooperativas que se baseiam nos princípios solidários reafirmam que a Economia Solidária vem como modelo de uma nova gestão, onde as pessoas que aderem a sua proposta, seja enquanto consumidoras ou produtoras, conseguem viver de uma maneira melhor (SINGER, 2002), pautada na igualdade de condições. Para tanto, tem-se que o Estado desempenha um importante papel na difusão e sustentação da Economia Solidária nos países, através da formulação das políticas públicas.

\subsection{POLÍTICA PÚBLICA DE ECONOMIA SOLIDÁRIA NO BRASIL}

No Brasil, segundo Singer (2004) tem-se como um marco no campo das políticas públicas para a Economia Solidária o ano de 2003, no então governo Lula, onde ocorreu a aprovação no Congresso Nacional da criação da Secretária Nacional de Economia Solidária (Senaes), vinculada ao Ministério do Trabalho e Emprego (MTE). Esta tem por objetivo principal difundir a prática de Economia Solidária pelo país, oferecendo apoio e incentivando o movimento.

Outras medidas foram adotadas a fim de estimular as políticas voltadas a Economia Solidária, sendo que conforme Singer (2004) o estado brasileiro começa então a entender que a crise de trabalho que adentrou o país desde a década de 80, fez emergir um processo de transformação social, ao qual se pode incluir as práticas de Economia Solidária. No ano de 2004, por exemplo, criou-se o Programa de Economia Solidária em Desenvolvimento, com o objetivo de atender necessidades e promover a difusão dos empreendimentos solidários (FARIA e SANCHEZ, 2011).

Tais políticas integradas leva a necessidade do apoio também dos governos estaduais e municipais, e a partir desta percepção o Fórum Brasileiro de Economia 
Solidária (FBES) começou a descentralizar suas atividades, passando a organizar fóruns também a nível estadual. Recursos começaram a ser destinados para diversos fins, a exemplo da construção de Centros de Referência de Economia Solidária e para a promoção de encontros, seminários e cursos voltados a instruir os indivíduos de conhecimento sobre o movimento e a gestão dos empreendimentos solidários.

Ainda se tem como exemplos de ações que levam a ampliação do movimento da Economia Solidária no Brasil, a implantação de incubadoras públicas de Economia popular e solidária criadas por algumas prefeituras, bem como a abertura de Bancos Comunitários que tem por objetivo oferecer serviços financeiros a população vulnerável (PRAXEDES, 2009).

Notadamente, ocorre um crescimento acentuado de novos empreendimentos solidários nos últimos tempos, onde estes se organizam de maneira democrática, solidária e cooperada, o que levou a adoção dessas iniciativas por parte da gestão pública em suas três esferas voltadas ao apoio às experiências solidárias, o que tem contribuindo de maneira direta para o fortalecimento desses empreendimentos. Estes passaram a ser vistos como meio de geração de emprego e renda para a população mais carente.

Contudo, apesar da difusão do movimento da Economia Solidária pelo Brasil, esta ainda passa por grandes desafios no campo das políticas públicas, sendo que se tem uma fragilidade dos EES em concorrer no mercado com grandes empresas capitalistas, bem como o acesso restrito aos recursos públicos que possam ser destinados ao fortalecimento desse novo modelo de produção. No entanto, Faria e Sanches (2011, p.435) afirmam que:

[...] podemos dizer que a Economia Solidária conquistou, nesses oito anos de implantação no governo federal, importante espaço no âmbito das politicas públicas sociais, de trabalho, geração de renda, inclusão produtiva, combate à miséria e à fome, cultura, do meio ambiente, etc, configurandose uma importante conquista do movimento da Economia Solidária no Brasil $[\ldots]$.

Esse processo de reconhecimento dos Empreendimentos Solidários como um caminho para o desenvolvimento e a inclusão de indivíduos no meio social, leva ao entendimento de que é possível disseminar a Economia Solidária como um novo 
modelo de produção que se contrapõe ao Capitalismo, e gera melhor qualidade de vida das pessoas na sociedade.

\section{ASPECTOS METODOLÓGICOS}

\subsection{CARACTERIZAÇÃO DO ESPAÇO ESTUDADO}

O Território Médio Sertão, definido pelo Conselho Estadual de Desenvolvimento Rural Sustentável (CEDRS), com o apoio técnico e metodológico da Secretaria de Desenvolvimento Territorial (SDT), é composto por 24 (vinte e quatro) municípios inseridos em duas Mesorregiões Geográficas (Sertão Paraibano e Borborema) e, dentro delas, em cinco Microrregiões Geográficas do Estado da Paraíba, segundo a divisão geográfica definida pelo Instituto Brasileiro de Geografia e Estatística - IBGE. O Território está localizado na área delimitada do semiárido brasileiro. Os municípios da Mesorregião Geográfica Sertão Paraibano são: a) $\mathbf{N a}$ Microrregião Geográfica de Patos: Areia de Baraúnas, Cacimba de Areia, Mãe d’Água, Passagem, Patos, Quixaba, Santa Teresinha, São José de Espinharas e São José do Bonfim; b) $\mathbf{N a}$ Microrregião do Piancó: Catingueira; c) $\mathbf{N a}$ Microrregião de Sousa: Condado, Malta e Vista Serrana e d) Na Microrregião Serra do Teixeira: Cacimbas, Desterro, Imaculada, Maturéia e Teixeira. Na Mesorregião Geográfica da Borborema, estão localizados os seguintes municípios: a) Microrregião Geográfica Seridó Ocidental Paraibano: Junco do Seridó, Salgadinho, Santa Luzia, São José do Sabugí, São Mamede e Várzea.

\subsection{CLASSIFICAÇÃO DA PESQUISA}

Quanto aos objetivos a pesquisa é de caráter descritivo, que tem como principal objetivo a descrição das características de uma determinada população ou grupo. Quanto aos procedimentos utilizados, trata-se de uma pesquisa documental e estudo de campo.

Quanto à abordagem do problema, a pesquisa é classificada como qualitativa, porque, de acordo com Diehl e Tatim (2006), a pesquisa foi construída com enfoque na compreensão e na interpretação dos significados dos próprios sujeitos. 
Dos 21 municípios do médio sertão presentes na região metropolitana de Patos, identificaram-se vários empreendimentos solidários. Para a coleta de dados, foi realizada uma pesquisa documental na ASDP (Ação Social Diocesana de Patos), observação dos pesquisadores em 3 (três) empreendimentos (em 3 municípios) da região, escolhidos por acessibilidade, e entrevistas semiestruturadas com os representantes desses empreendimentos. Entrevistou-se também, o representante da subsecretaria da Economia Solidária e Segurança Alimentar, José Anchieta de Assis. De acordo com Diehl e Tatim (2006: 66), a entrevista é um procedimento utilizado na investigação social, para a coleta de dados ou para ajudar no diagnóstico ou no tratamento de um problema social.

Para a análise dos dados, relacionou-se a pesquisa documental com as falas dos entrevistados realizando uma análise interpretativa, levando em consideração também a observação dos pesquisadores.

\section{ANÁLISE DOS RESULTADOS}

\subsection{MAPEAMENTO DOS EMPREENDIMENTOS DE ECONOMIA SOLIDÁRIA NA REGIÃO DO MÉDIO SERTÃO PARAIBANO}

A ASDP (AÇÃO SOCIAL DIOCESANA DE PATOS) mapeou os empreendimentos solidários do médio Sertão paraibano em 07 (sete) microrregiões: Vale do Sabugi, Vale das Espinharas, Vale do Médio Piranhas, Vale do Piancó, Serra de Princesa, Serra do Teixeira, Serra do Cariri.

A ASDP (2019) mostra as 56 experiências de Economia Solidária (ES), nas sete microrregiões do médio sertão através do quadro abaixo.

Percebe-se, de acordo com esses dados, que das 56 experiências mapeadas, 43 estão localizadas em territórios camponeses e 13 em territórios quilombolas, estando envolvidas 1004 pessoas, dentre às quais $53,1 \%$ são do gênero feminino e $46,9 \%$ do gênero masculino. Há, entre as experiências mapeadas, uma diversidade de expressões de Economia Solidária, considerando as particularidades de cada grupo e o alinhamento possível vem se fazendo, por meio dos processos formativos.

O Quadro 1 dá uma visão panorâmica de como os grupos estão distribuídos nas sete microrregiões, conforme as expressões de Economia Solidária até então identificadas. Identificamos assim um maior número de experiência no Vale do 
Sabugi (VS) com um total de 20, seguido do Vale do Piancó (VP) com 10 e Vale do Espinharas (VE) com 9 (nove).

Quadro 1 - Visão panorâmica das expressões de Economia Solidária por microrregião.

\begin{tabular}{|c|c|c|c|c|c|c|c|c|c|}
\hline Ex & Experiências identificadas & VS & VE & $\overline{\mathrm{AP}}$ & $/ P$ & SP & ST & SC & Total \\
\hline AT & $\begin{array}{l}\text { Barro, crochê, costura, madeira, palha, materiais } \\
\text { recicláveis, sisal, decoupagem. }\end{array}$ & 04 & - & - & - & 01 & 02 & 01 & 08 \\
\hline BP & $\begin{array}{l}\text { Polpa de frutas, doces, arroz vermelho, culinária (bolos, } \\
\text { cocadas, farinhas, doces). }\end{array}$ & 02 & 01 & - & 02 & - & - & - & 05 \\
\hline $\mathrm{CA}$ & Abelhas, aves de terreiro, caprinos, ovinos e bovinos. & 02 & 02 & - & 02 & 2 & - & - & 8 \\
\hline CJ & $\begin{array}{l}\text { Venda na própria comunidade, feira da agricultura } \\
\text { familiar, venda direta em domicílio, programas de } \\
\text { fortalecimento da agricultura familiar, ponto fixo de } \\
\text { comercialização. }\end{array}$ & 01 & 02 & 02 & 02 & 01 & - & - & 08 \\
\hline CS & $\begin{array}{l}\text { Fundos rotativos, consórcios comunitários, bazar, } \\
\text { quermesses }\end{array}$ & 02 & 01 & 02 & 02 & - & - & - & 07 \\
\hline $\mathrm{EC}$ & Salão de beleza, manicure e pedicure, Filhas do Rei. & - & & & & & - & 02 & 02 \\
\hline OB & $\begin{array}{l}\text { Associações comunitárias, centrais de associações, } \\
\text { cooperativas, colônia de pescadores }\end{array}$ & 02 & - & 01 & 01 & 01 & 01 & - & 06 \\
\hline SB & $\begin{array}{l}\text { Bancos de Sementes Comunitários, produção de mudas } \\
\text { nativas e adaptadas, produção de cactos e suculentas. }\end{array}$ & 07 & 03 & - & 01 & - & 01 & - & 12 \\
\hline \multirow{2}{*}{\multicolumn{10}{|c|}{ Legenda }} \\
\hline & & & & & & & & & \\
\hline \multicolumn{10}{|c|}{$\begin{array}{l}\text { Ex (Expressões de Economia Solidária), AT (Artesanato), BP (Beneficiamento da Produção), CA (Criação } \\
\text { Animal, CJ (Comércio Justo e Solidário), CS (Crédito Solidário), EC (Embelezamento e Estética Corporal), OB } \\
\text { (Organizações de Base), SB (Em defesa da sociobiodiversidade), VS (Vale do Sabugi), VE (Vale das } \\
\text { Espinharas), MP (Vale do Médio Piranhas), VP (Vale do Piancó), SP (Serra de Princesa), ST (Serra do } \\
\text { Teixeira), SC (Serra do Cariri). }\end{array}$} \\
\hline
\end{tabular}

Fonte: ASDP, 2019.

Das 56 experiências mapeadas, conforme as expressões identificadas, observam-se 12 experiências que se classificam enquanto defesa da Sociobiodiversidade (21,4\%), 08 experiências de Artesanato (14,3\%), 08 experiências de Criação Animal (14,3\%), 08 experiências de Comércio Justo e Solidário (14,3\%), 07 experiências de Crédito Solidário (12,5\%), 06 experiências de Organizações de Base (10,7\%), 05 experiências de Beneficiamento da Produção (8,9\%), 02 experiências de Estética e Embelezamento Corporal (3,6\%).

O Quadro 2 apresenta as Experiências de Economia Solidária (ES) que foram mapeadas no Vale do Sabugi, com destaques para os municípios de São José do Sabugi (SJS), Santa Luzia (SLZ) e Várzea (VRZ), com destaque para a experiências de CA (abelhas, aves, caprinos etc) em São José do Sabugi. 
Quadro 2 - Experiências de ES mapeadas no Vale do Sabugi.

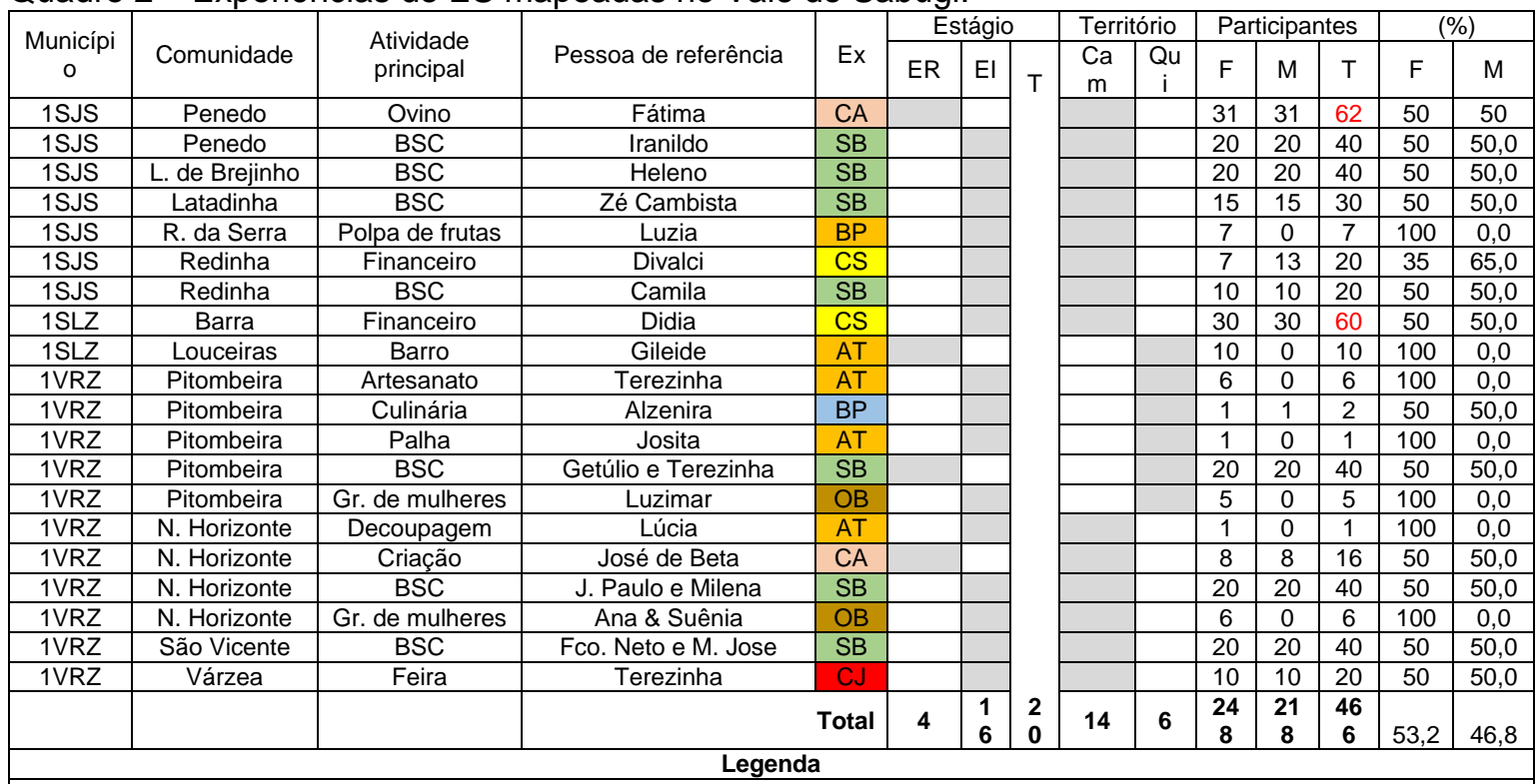

Número 1 (referência à microrregião do Vale do Sabugi), Ex (Expressões de Economia Solidária), SJS (São José do Sabugi), SLZ (Santa Luzia), VRZ (Várzea), ER (Experiência Referencial), El (Experiência Iniciante), T (Total), Cam (Camponês), Qui (Quilombola), F (Feminino), M (Masculino).

AT (Artesanato), BP (Beneficiamento da Produção), CA (Criação Animal, CJ (Comércio Justo e Solidário), CS (Crédito Solidário), EC (Embelezamento e Estética Corporal), OB (Organizações de Base), SB (Em defesa da sociobiodiversidade).

Fonte: ASDP, 2019

O Quadro 3 apresenta as Experiências de Economia Solidária (ES) que foram mapeadas no Vale das Espinharas, com destaque para a Feira da agricultura familiar (CJ) e bancos de sementes e produção de mudas (SB) no município de Patos.

Quadro 3 - Experiências de ES mapeadas no Vale das Espinharas.

\begin{tabular}{|c|c|c|c|c|c|c|c|c|c|c|c|c|c|c|}
\hline \multirow{2}{*}{ Município } & \multirow{2}{*}{ Comunidade } & \multirow{2}{*}{$\begin{array}{l}\text { Atividade } \\
\text { principal }\end{array}$} & \multirow{2}{*}{ Pessoa de referência } & \multirow{2}{*}{ Ex } & \multicolumn{3}{|c|}{ Estágio } & \multicolumn{2}{|c|}{ Território } & \multicolumn{3}{|c|}{ Participantes } & \multicolumn{2}{|c|}{$(\%)$} \\
\hline & & & & & ER & $\mathrm{El}$ & $\mathrm{T}$ & Cam & Qui & $\mathrm{F}$ & $\mathrm{M}$ & $\mathrm{T}$ & $\mathrm{F}$ & $\mathrm{M}$ \\
\hline 2POS & Patos & Feira & Lúcio & CJ & & & & & & 17 & 16 & 33 & 51,5 & 48,5 \\
\hline 2POS & Boi do Brito & Criação & Claudeci & $\mathrm{CA}$ & & & & & & 10 & 0 & 10 & 100,0 & 0,0 \\
\hline 2POS & Ass. Patativa & $\begin{array}{c}\text { Jardim } \\
\text { Sertanejo }\end{array}$ & Val e Rabay & SB & & & & & & 1 & 2 & 3 & 33,3 & 66,7 \\
\hline 2POS & Trincheira & Criação & Antônio & $\mathrm{CA}$ & & & & & & 4 & 5 & 9 & 44,4 & 55,6 \\
\hline 2POS & Trincheira & $\mathrm{BSC}$ & José Benício e Jeany & SB & & & & & & 20 & 20 & 40 & 50,0 & 50,0 \\
\hline $2 \mathrm{POS}$ & Mocambo & BSC & Lúcio & SB & & & & & & 20 & 20 & 40 & 50,0 & 50,0 \\
\hline $2 \mathrm{CDA}$ & $\begin{array}{c}\text { Cacimba de } \\
\text { Boi }\end{array}$ & Polpa de frutas & Zé & $\mathrm{BP}$ & & & & & & 3 & 3 & 6 & 50,0 & 50,0 \\
\hline 2CDA & Alto Vermelho & Financeiro & Maria & CS & & & & & & 8 & 7 & 15 & 53,3 & 46,7 \\
\hline $2 S T Z$ & $\begin{array}{c}\text { Santa } \\
\text { Terezinha }\end{array}$ & Feira & Canela Seca & CJ & & & & & & 4 & 4 & 8 & 50,0 & 50,0 \\
\hline & & & & otal & 4 & 5 & 09 & 9 & 0 & 87 & 77 & 164 & 53,0 & 47,0 \\
\hline
\end{tabular}

$$
\text { Legenda }
$$

Número 2 (referência à microrregião do Vale das Espinharas), Ex (Expressões de Economia Solidária), POS (Patos), CDA (Cacimba de Areia), STZ Santa Terezinha, ER (Experiência Referencial), El (Experiência Iniciante), T (Total). AT (Artesanato), BP (Beneficiamento da Produção), CA (Criação Animal, CJ (Comércio Justo e Solidário), CS (Crédito Solidário), EC (Embelezamento e Estética Corporal), OB (Organizações de Base), SB (Em defesa da sociobiodiversidade).

Fonte: ASDP, 2019.

O Quadro 4 apresenta as Experiências de Economia Solidária (ES) que foram mapeadas no Vale do Médio Piranhas, com destaque para o município de $\underline{\text { Condado }}$ 
com atividades de consórcio comunitários (CS) e programa de fortalecimento da agricultura familiar - feira (CJ).

Quadro 4 - Experiências de ES mapeadas no Vale do Médio Piranhas.

\begin{tabular}{|c|c|c|c|c|c|c|c|c|c|c|c|c|c|c|}
\hline \multirow[b]{2}{*}{ Município } & \multirow[b]{2}{*}{ Comunidade } & \multirow{2}{*}{$\begin{array}{l}\text { Atividade } \\
\text { principal }\end{array}$} & \multirow[b]{2}{*}{$\begin{array}{l}\text { Pessoa de } \\
\text { referência }\end{array}$} & \multirow[b]{2}{*}{ Ex } & \multicolumn{3}{|c|}{ Estágio } & \multicolumn{2}{|c|}{$\begin{array}{l}\text { Território } \\
\end{array}$} & \multicolumn{3}{|c|}{ Participantes } & \multicolumn{2}{|c|}{$(\%)$} \\
\hline & & & & & ER & EI & T & $\begin{array}{l}\mathrm{Ca} \\
\mathrm{m}\end{array}$ & Qui & $\mathrm{F}$ & M & $\mathrm{T}$ & $\mathrm{F}$ & M \\
\hline $3 \mathrm{CON}$ & Várzea do Feijão & Financeiro & Silvanir & $\begin{array}{l}C \\
S\end{array}$ & & & & & & 25 & $\begin{array}{l}2 \\
5\end{array}$ & 50 & 50,0 & 50,0 \\
\hline $3 \mathrm{CON}$ & Condado & Feira & Batista & $\mathrm{CJ}$ & & & & & & 8 & 8 & 16 & 50,0 & 50,0 \\
\hline $3 \mathrm{CON}$ & Condado & Cooperativa & Paulo & $\mathrm{OB}$ & & & & & & & & & & \\
\hline $3 \mathrm{MAL}$ & Malta & Feira & Doralice & $\mathrm{CJ}$ & & & & & & 5 & 5 & 10 & 50,0 & 50,0 \\
\hline 3VSR & Acari & Financeiro & Antonio & $\begin{array}{l}\mathrm{C} \\
\mathrm{S}\end{array}$ & & & & & & 17 & $\begin{array}{l}1 \\
7 \\
\end{array}$ & 34 & 50,0 & 50,0 \\
\hline & & & & otal & 0 & 4 & 4 & 4 & 0 & 55 & $\begin{array}{l}5 \\
5\end{array}$ & 110 & 50,0 & 50,0 \\
\hline
\end{tabular}

Número 3 (referência à microrregião do Vale do Médio Piranhas), Ex (Expressões de Economia Solidária), CON (Condado), VSR (Vista Serrana), MAL (Malta), ER (Experiência Referencial), El (Experiência Iniciante), Cam (Camponês), Qui (Quilombola), F (Feminino), M (Masculino), T (Total). AT (Artesanato), BP (Beneficiamento da Produção), CA (Criação Animal, CJ (Comércio Justo e Solidário), CS (Crédito Solidário), EC (Embelezamento e Estética Corporal), OB (Organizações de Base), SB (Em defesa da sociobiodiversidade).

Fonte: ASDP, 2019.

O Quadro 5 apresenta as Experiências de Economia Solidária (ES) que foram mapeadas no Vale do Piancó, com maior expressão para Santana dos Garrotes com as experiências de Forragem (BP), Bancos de sementes (SB) e Consórcios comunitários (CS).

Quadro 5 - Experiências de ES mapeadas no Vale do Piancó.

\begin{tabular}{|c|c|c|c|c|c|c|c|c|c|c|c|c|c|c|}
\hline \multirow[t]{2}{*}{ Município } & \multirow[t]{2}{*}{ Comunidade } & \multirow{2}{*}{$\begin{array}{l}\text { Atividade } \\
\text { principal }\end{array}$} & \multirow[t]{2}{*}{ Pessoa de referência } & \multirow[t]{2}{*}{ Ex } & \multicolumn{3}{|c|}{ Estágio } & \multicolumn{2}{|c|}{ Território } & \multicolumn{3}{|c|}{ Participantes } & \multicolumn{2}{|c|}{$(\%)$} \\
\hline & & & & & ER & $\mathrm{El}$ & $\mathrm{T}$ & Cam & Qui & $\mathrm{F}$ & $\mathrm{M}$ & $T$ & $\mathrm{~F}$ & $\mathrm{M}$ \\
\hline 4STG & Curral Velho & Forragem & Cleoberto & $\mathrm{BP}$ & & & & & & 10 & 10 & 20 & 50,0 & 50,0 \\
\hline 4STG & $\begin{array}{c}\text { Maracujá de } \\
\text { Baixo }\end{array}$ & BSC & Ana Santos & SB & & & & & & 20 & 19 & 39 & 51,3 & 48,7 \\
\hline 4STG & $\begin{array}{c}\text { Maracujá de } \\
\text { Baixo }\end{array}$ & Financeiro & Damiana & CS & & & & & & 20 & 19 & 39 & 51,3 & 48,7 \\
\hline 4STG & Curral Velho & Arroz Vermelho & Agostinho & $\mathrm{BP}$ & & & & & & 9 & 9 & 18 & 50,0 & 50,0 \\
\hline 4STG & S. dos Garrotes & Feira & Ivonete & CJ & & & & & & 3 & 3 & 6 & 50,0 & 50,0 \\
\hline $4 \mathrm{NOL}$ & Andreza & Financeiro & Lourdinha & CS & & & & & & 5 & 5 & 10 & 50,0 & 50,0 \\
\hline 4CTG & Poço de Baixo & Criação & Donato & $\mathrm{CA}$ & & & & & & 2 & 1 & 3 & 66,7 & 33,3 \\
\hline $4 \mathrm{CTG}$ & Poço Deserto & Criação & Judivan & CA & & & & & & 2 & 1 & 3 & 66,7 & 33,3 \\
\hline 4CTG & Catingueira & Feira & Judivan da Feira & CJ & & & & & & 5 & 5 & 10 & 50,0 & 50,0 \\
\hline $4 \mathrm{PIA}$ & Peixoto & Pescadores & Vavá & $\mathrm{OB}$ & & & & & & 6 & 6 & 12 & 50,0 & 50,0 \\
\hline & & & & Total & 2 & 8 & 10 & 10 & 0 & 82 & 78 & 160 & 51,3 & 48,8 \\
\hline
\end{tabular}

Número 4 (referência à microrregião do Vale do Piancó), Ex (Expressões de Economia Solidária), STG (Santana dos Garrotes), NOL (Nova Olinda), PIA (Piancó), ER (Experiência Referencial), El (Experiência Iniciante), Cam (Camponês), Qui (Quilombola), F (Feminino), M

(Masculino), T (Total). AT (Artesanato), BP (Beneficiamento da Produção), CA (Criação Animal, CJ (Comércio Justo e Solidário), CS (Crédito Solidário), EC (Embelezamento e Estética Corporal), OB (Organizações de Base), SB (Em defesa da sociobiodiversidade).

Fonte: ASDP, 2019.

O Quadro 6 apresenta as Experiências de Economia Solidária (ES) que foram mapeadas na Serra de Princesa, com maior número (22) no município de Água Branca com as atividades de artesanatos (AT) e Apicultura (CA). 
Quadro 6 - Experiências de ES mapeadas na Serra de Princesa.

\begin{tabular}{|c|c|c|c|c|c|c|c|c|c|c|c|c|c|c|}
\hline \multirow{2}{*}{$\begin{array}{c}\text { Municípi } \\
\text { o }\end{array}$} & \multirow[b]{2}{*}{ Comunidade } & \multirow{2}{*}{$\begin{array}{l}\text { Atividade } \\
\text { principal }\end{array}$} & \multirow{2}{*}{$\begin{array}{l}\text { Pessoa de } \\
\text { referência }\end{array}$} & \multirow[b]{2}{*}{ Ex } & \multicolumn{3}{|c|}{ Estágio } & \multicolumn{2}{|c|}{ Território } & \multicolumn{3}{|c|}{ Participantes } & \multicolumn{2}{|c|}{$(\%)$} \\
\hline & & & & & ER & $\mathrm{EI}$ & $T$ & $\begin{array}{c}\mathrm{Ca} \\
\mathrm{m}\end{array}$ & Qui & $\mathrm{F}$ & M & $\mathrm{T}$ & $\mathrm{F}$ & M \\
\hline $5 A B C$ & Lagoinha & Artesanato & Maria & AT & & & & & & 6 & 4 & 10 & 60,0 & 40,0 \\
\hline $5 A B C$ & Lagoinha & Apicultura & Jackson & $\mathrm{CA}$ & & & & & & 0 & 12 & 12 & 0,0 & 100 \\
\hline 5TAV & $\begin{array}{c}\text { Domingos } \\
\text { Ferreira }\end{array}$ & $\begin{array}{l}\text { Grupo de } \\
\text { mulheres }\end{array}$ & Maria José & $\mathrm{OB}$ & & & & & & 3 & 0 & 3 & 100 & 0,0 \\
\hline $5 \mathrm{PIS}$ & Princesa Isabel & Comércio & Beta & CJ & & & & & & 3 & 0 & 3 & 100 & 0,0 \\
\hline $5 \mathrm{PIS}$ & Areias & Criação Animal & Marlene & $\mathrm{CA}$ & & & & & & 5 & 5 & 10 & 50,0 & 50,0 \\
\hline & & & & Total & 1 & 4 & 5 & 4 & 1 & $\begin{array}{l}1 \\
7\end{array}$ & 21 & 38 & 44,7 & 55,3 \\
\hline
\end{tabular}

Número 5 (referência à microrregião da Serra de Princesa), Ex (Expressões de Economia Solidária), ABC (Água Branca), TAV (Tavares), PIS (Princesa Isabel), ER (Experiência Referencial), EI (Experiência Iniciante), Cam (Camponês), Qui (Quilombola), F (Feminino), M (Masculino), T (Total). AT (Artesanato), BP (Beneficiamento da Produção), CA (Criação Animal, CJ (Comércio Justo e Solidário), CS (Crédito Solidário), EC (Embelezamento e Estética Corporal), OB (Organizações de Base), SB (Em defesa da sociobiodiversidade).

Fonte: ASDP, 2019.

\section{O Quadro 7 apresenta as Experiências de Economia Solidária (ES) que foram} mapeadas na Serra do Teixeira, com 30 experiências em Cacimbas de artesanato (AT) e Bancos de sementes e 10 em Matureia de artesanato.

Quadro 7 - Experiências de ES mapeadas na Serra do Teixeira.

\begin{tabular}{|c|c|c|c|c|c|c|c|c|c|c|c|c|c|c|}
\hline \multirow{2}{*}{$\begin{array}{l}\text { Municípi } \\
\text { o }\end{array}$} & \multirow[b]{2}{*}{ Comunidade } & \multirow[b]{2}{*}{ Atividade principal } & \multirow{2}{*}{$\begin{array}{l}\text { Pessoa de } \\
\text { referência }\end{array}$} & & \multicolumn{3}{|c|}{ Estágio } & \multicolumn{2}{|c|}{ Território } & \multicolumn{3}{|c|}{ Participantes } & \multicolumn{2}{|c|}{ Porcentagem } \\
\hline & & & & & ER & El & $\mathrm{T}$ & $\begin{array}{c}\mathrm{Ca} \\
\mathrm{m}\end{array}$ & Qui & $\mathrm{F}$ & M & T & $\mathrm{F}$ & M \\
\hline $6 C A C$ & Serra Feia & Artesanato & Rosenira & AT & & & & & & 10 & 0 & $\begin{array}{l}1 \\
0\end{array}$ & 100 & 0,0 \\
\hline $6 \mathrm{CAC}$ & Chã e Aracati & BSC & Esmeralda & SB & & & & & & 10 & $\begin{array}{l}1 \\
0\end{array}$ & $\begin{array}{l}2 \\
0\end{array}$ & 50,0 & 50,0 \\
\hline $6 \mathrm{CAC}$ & Chã e Aracati & Grupo de mulheres & Leandra & $\mathrm{OB}$ & & & & & & 4 & 0 & 4 & 100 & 0,0 \\
\hline 6MAT & Matureia & Artesanato & Maria José & AT & & & & & & 6 & 4 & 1 & 600 & 40.0 \\
\hline & & & & Total & 2 & 2 & 4 & 1 & 3 & 30 & $\begin{array}{l}1 \\
4 \\
\end{array}$ & $\begin{array}{l}4 \\
4 \\
\end{array}$ & 68,2 & 31,8 \\
\hline
\end{tabular}

Número 6 (referência à microrregião da Serra do Teixeira), Ex (Expressões de Economia Solidária), CAC (Cacimbas), MAT (Matureia), ER (Experiência Referencial), El (Experiência Iniciante), Cam (Camponesa), Qui (Quilombola), F (Feminino), M (Masculino), T (Total). AT (Artesanato), BP (Beneficiamento da Produção), CA (Criação Animal, CJ (Comércio Justo e Solidário), CS (Crédito Solidário), EC (Embelezamento e Estética Corporal), OB (Organizações de Base), SB (Em defesa da sociobiodiversidade).

Fonte: ASDP, 2019.

\section{O Quadro 8 apresenta as Experiências de Economia Solidária (ES) que foram} mapeadas na Serra do Cariri com 16 experiências em Livramento de embelezamento (EC) e artesanato (AT).

Quadro 8 - Experiências de ES mapeadas na Serra do Cariri.

\begin{tabular}{|c|c|c|c|c|c|c|c|c|c|c|c|c|c|c|}
\hline \multirow{2}{*}{$\begin{array}{c}\text { Municípi } \\
\text { o }\end{array}$} & \multirow{2}{*}{ Comunidade } & \multirow{2}{*}{ Atividade principal } & \multirow{2}{*}{$\begin{array}{l}\text { Pessoa de } \\
\text { referência }\end{array}$} & \multirow{2}{*}{ Ex } & \multicolumn{3}{|c|}{ Estágio } & \multicolumn{2}{|c|}{ Território } & \multicolumn{3}{|c|}{ Participantes } & \multicolumn{2}{|c|}{$\begin{array}{c}\text { Porcentage } \\
\mathrm{m}\end{array}$} \\
\hline & & & & & ER & El & $\mathrm{T}$ & $\begin{array}{c}\mathrm{Ca} \\
\mathrm{m}\end{array}$ & Qui & $\mathrm{F}$ & M & $\mathrm{T}$ & $\mathrm{F}$ & M \\
\hline 7LIV & Sussuarana & Decoupagem & Hosana & AT & & & & & & 3 & 0 & 3 & 100 & 0,0 \\
\hline 7LIV & Sussuarana & Salão de beleza & Valéria & EC & & & & & & 3 & 0 & 3 & 100 & 0,0 \\
\hline 7LIV & Sussuarana & Embelezamento & Cristiane e Rosa & EC & & & & & & 6 & 2 & 8 & 75,0 & 25,0 \\
\hline \multirow{2}{*}{\multicolumn{15}{|c|}{ Legenda }} \\
\hline & & & & & & & & & & & & & & \\
\hline \multicolumn{15}{|c|}{$\begin{array}{l}\text { Número } 7 \text { (referência à microrregião da Serra do Cariri), Ex (Expressões de Economia Solidária), LIV (Livramento), ER (Experiência } \\
\text { Referencial), El (Experiência Iniciante), Cam (Camponesa), Qui (Quilombola), F (Feminino), M (Masculino), T (Total). AT (Artesanato), BP } \\
\text { (Beneficiamento da Produção), CA (Criação Animal, CJ (Comércio Justo e Solidário), CS (Crédito Solidário), EC (Embelezamento e Estética } \\
\text { Corporal), OB (Organizações de Base), SB (Em defesa da sociobiodiversidade). }\end{array}$} \\
\hline
\end{tabular}

Fonte: ASDP, 2019. 


\subsection{PERFIL ECONÔMICO DOS EMPREENDIMENTOS SOLIDÁRIOS} IDENTIFICADOS E SUA RELAÇÃO COM OS PRINCÍPIOS DA ECONOMIA SOLIDÁRIA - TRÊS EXEMPLOS

Dentre os vários empreendimentos econômicos solidários identificados na região, evidenciou-se 3 (três) destes, sendo eles: a Associação de Apicultores no município de Condado-PB, a Feira de Agricultura Familiar realizada no município de Patos-PB e a Associação Comunitária de Penedo localizada na zona rural do município de São José do Sabugi-PB.

A Associação dos Apicultores e Produtores Rurais de Condado-PB (AAPRC) foi criada em 09 de Março de 2007, onde fazem parte atualmente 15 famílias, sendo estas da zona rural e urbana. Destas famílias, de duas ou três pessoas participa do empreendimento, o que leva ao entendimento de que a associação é constituída de aproximadamente 40 membros.

Quanto a renda obtida pelos associados, esta é variável, o que configura a associação de apicultores como uma fonte para a obtenção de renda destes membros. No concernente a tomada de decisões, estas são decididas por todos os membros, onde todos têm direito a expor suas opiniões e a votarem, o que evidencia o princípio democrático da economia solidária.

Evidenciou-se também a solidariedade e a cooperação existente entre os membros associados, onde esses ajudam uns aos outros, principalmente ensinando o processo de produção do mel e capacitando novos membros que chegam à associação, o que remete aos princípios norteadores da economia solidária, sendo, portanto, a associação entendida como um empreendimento solidário.

Já a Feira da Agricultura Familiar realizada no município de Patos-PB envolve diversos empreendedores familiares da região, onde em visita ao local da realização desta entrevistou-se o Sr. José Benício Morais Monteiro, residente no município de Patos-PB e participante da feira.

Em conversa com Seu José Benício, este afirmou que há 11 (onze) anos trabalha juntamente com sua família no cultivo de verduras. Os produtos são comercializados por meio da feira da agricultura familiar realizada na cidade de Patos-PB as quintas feiras, bem como podem ser encontradas na residência da família. Fazem parte do empreendimento solidário 10 (dez) pessoas, que são de 
uma mesma família, onde estes tem idade média entre 30 e 50 anos, e são em sua maioria homens.

Perguntado sobre como as tarefas são divididas entre o grupo, seu José Benício afirma que a maioria dos membros são responsáveis pelo cultivo das verduras e legumes, enquanto ele e sua esposa além de ajudarem no processo de produção, também são encarregados pela venda dos produtos. Quanto as decisões inerentes ao grupo, estas são tomadas em conjunto, tendo a participação de todos os envolvidos. Portanto, estão evidentes os princípios da democracia, da autogestão e da cooperação no empreendimento analisado, bem como o cuidado com o meio ambiente, já que não se faz uso de agrotóxicos na produção das verduras e legumes.

Outro empreendimento da região observado foi a Associação Comunitária de Penedo, que se localiza no município de São José do Sabugi. O entrevistado foi o Sr. Irenaldo, membro da associação. Este relatou que o intuito da criação da associação há 6 (anos) foi melhorar a vida das pessoas na comunidade.

Seu Irenaldo afirma que os trabalhos desenvolvidos pela associação são voltados a produção de ensilagem, bem como a troca de serviços, onde todos se ajudam, o que remete ao princípio da cooperação evidenciado pela economia solidária. Este ainda confirma que o grupo é pequeno, envolvendo cerca de 6(seis) a 8(oito) pessoas, que não são de uma mesma família. Evidencia-se, portanto, a inclusão social apontada nas discussões sobre o modo de produção alternativo da economia solidária.

No concernente a renda obtida, esta é de até um salário mínimo, mas que contribui para a geração de renda para as famílias envolvidas. Sendo, portanto, os ganhos divididos de modo igualitário. Quanto a divisão de tarefas, esta se dá pela condição física e conhecimento dos membros, de modo que promova ganhos à todos. Já as decisões pertinentes à associação são tomadas por todos os membros, aonde por meio de discussões e debates se chega a uma conclusão e decisão final. Tem-se, portanto, que na Associação de Penedo evidenciam-se princípios de economia solidária, a exemplo do princípio da democracia.

De modo geral, e considerando os apontamentos feitos a partir de cada representante dos empreendimentos solidários analisados, pode-se apontar que ambos apresentam fortes características solidárias, onde estes buscam por bem estar social dos participantes, por inclusão social e geração de renda. 
4.3 AÇÕES DO PODER PÚBLICO (ESTADUAL/MUNICIPAL) IDENTIFICADAS PARA O INCENTIVO À ECONOMIA SOLIDÁRIA DA REGIÃO, E A IMPORTÂNCIA DA ES PARA A REGIÃO DO SERTÃO E OS SEUS PRINCIPAIS DESAFIOS

$\mathrm{Na}$ perspectiva de identificar ações dos poderes públicos estaduais/municipais que incentivem as práticas de economia solidária na região investigada, entrevistou-se o Sr. José de Anchieta, ex-presidente da Casa de Economia Solidária do município de Pombal-PB, e membro atuante do movimento que envolve os empreendimentos e empreendedores solidários.

Acerca do apoio da gestão pública ao movimento de economia solidária, que viesse a fomentar essas práticas, Seu Anchieta aponta uma visão pessimista, evidenciando que a maioria dos municípios não valoriza ou desconhecem os empreendimentos solidários e a sua importância para o desenvolvimento social e econômico.

No que concerne às ações do poder público estadual, evidencia-se a existência do Plano Estadual de Economia Solidária, que embora tenha contribuído para o movimento da economia solidária, ainda precisa da aprovação de uma lei estadual que está em fase de tramitação na assembleia do estado para funcionar plenamente. Este ainda relata que há omissão das secretarias estaduais do governo paraibano, em querer acolher e praticar o plano.

Já sobre incentivos da gestão pública, relata-se uma pequena participação de algumas Secretarias que colaboram em situações isoladas, e ainda afirma a falta de um planejamento coletivo. Evidencia também a criação da Secretaria Nacional de Economia Solidária, que poderia trazer grandes benefícios para a região, porém esta foi reduzida a departamento nas últimas gestões, o que significa um retrocesso no reconhecimento da ES como meio viável de produção.

Há, portanto, na percepção do entrevistado, uma omissão dos gestores municipais e estaduais no que diz respeito a incentivos e ações que venham a beneficiar os empreendimentos econômicos solidários. Contudo, este também ressalta o apoio de algumas instituições, a exemplo da EMATER, que tem buscado apoiar e incentivar os empreendedores solidários, colaborando com a realização da feira da Agricultura Familiar, que está sendo realizada em alguns municípios.

No que remete a importância dos Empreendimentos Solidários na região e seus principais desafios, tem-se que o entrevistado evidencia de imediato os 
envolvidos no processo de ES, tendo-os como aqueles que mais tendem a se preocuparem com a saúde pública, sendo que alertam para os riscos causados pelo uso de agrotóxicos, por exemplo. Estes buscam uma harmonização com a natureza, e são conscientes das problemáticas ambientais. Confirma a geração de renda para as famílias envolvidas nos empreendimentos solidários, e o envolvimento de mulheres, jovens e crianças, o que reflete modos de inclusão social, minimizando desigualdades.

E por fim, perguntado dos desafios evidentes dos EES, o Sr. José Anchieta aponta os internos, inerentes a cada empreendimento. Afirma que muitos destes empreendedores solidários ainda não tiveram a oportunidade de participar de capacitações que viessem a mostra-los como gerir seus negócios. Como desafios de um modo geral, que afetam a todos os EES, ele evidencia o difícil acesso ao mercado, principalmente para aqueles que participam da agricultura familiar. Tem-se como o grande desafio a obtenção do registro e dos selos, que permitem a comercialização regular desses produtos. Enquanto política pública estadual, o entrevistado coloca como um dos maiores desafios o apoio do governo a todo esse processo por meio de agências de vigilância sanitária.

Portanto, percebe-se que os EES ainda enfrentam grandes desafios e conta com um mínimo ou nenhum apoio dos gestores públicos. Logo, na região analisada percebe-se uma série de empreendimentos solidários e uma diversidade de atividades desenvolvidas, que podem contribuir efetivamente para 0 desenvolvimento local, porém ainda falta dá visibilidade a estes negócios, bem como contar com um apoio contínuo da gestão pública.

\section{CONSIDERAÇÕES FINAIS}

A finalidade deste estudo foi mapear os empreendimentos econômicos solidários existentes na região do Sertão Paraibano, bem como identificar as ações do poder público que incentivem os EES, observando a presença dos princípios solidários nesses locais e a importância destes para a promoção do desenvolvimento local. Como resultado da pesquisa, ressalta-se a identificação de um número considerável de empreendimentos solidários, estando estes localizados nas diversas cidades que fazem parte da região do Sertão. 
Dentre os EES analisados, localizados em cidades diferentes, se constatou a presença de princípios solidários norteadores da Economia Solidária, como a democracia, a cooperação, a solidariedade, a autogestão e o cuidado com o meio ambiente. Estes têm, portanto, se configurado como importantes fontes de geração de renda e inclusão social para aqueles que são excluídos ou explorados pelo sistema capitalista.

Verificou-se ainda, que estes empreendimentos solidários estão se fortalecendo na região, porém se evidencia vários desafios a serem enfrentados para que de fato estes sejam reconhecidos, e nessa perspectiva observa-se que a falta de apoio dos gestores públicos estaduais e municipais acabam por retroceder o processo de difusão da economia solidária no Sertão. Embora se perceba alguns eventos importantes, a exemplo da criação do plano Estadual da Economia Solidária, ainda inexistem políticas públicas que venham a promover e fomentar a difusão da economia solidária como meio viável de produção.

O resultado desse estudo também demonstra que o ambiente de Economia Solidária difundido pela região do Sertão se configura num rico campo de experiências econômicas e sociais, que se melhor explorados podem contribuir para a construção de uma sociedade mais justa e solidária.

\section{REFERÊNCIAS}

ALBUQUERQUE, P. Autogestão. In CATTANI, A. A outra economia. Porto Alegre: Veraz Editores, 2003.

AÇÃO SOCIAL DIOCESANO DE PATOS - ASDP - Dados online disponível em http://asdppb.org/, 2019.

COLE, G. D. H. A Century of Co-Operation. Manchester, Cooperative Union Ltd., 1944.

CRUZ, Lindalva. Alves. CAVALCANTI, Ligia Maria Alves de. PESSOA, Lindovon Dias. Economia Solidária e gênero: reflexão teórico-prática. 2018.

COSTA, Sunamita Iris Rodrigues Borges. Tecnologias Alternativas: repensando a agricultura familiar. Curitiba: Appris, 2015.

DIELHL, Astor Antônio \& TATIM, Denise Carvalho. Pesquisa em ciências sociais aplicadas: métodos e técnicas. São Paulo: Pearson Prentice Hall, 2004. 
FARIA, Maurício Sardá de; SANCHEZ, Fábio José Bechara. A Economia Solidária no Governo Federal: intersetorialidade, transversalidade e cooperação Internacional. IN: Édi Benini ...[et al] (organizadores). Gestão pública e sociedade: fundamentos e políticas públicas de economia solidária. 1.ed. São Paulo: Outras Expressões, 2011.

FERREIRA, Elenar. "A cooperação no MST: da luta pela terra à gestão coletiva dos meios de produção." IN SINGER e SOUZA (ong.). Economia Solidária no Brasil: autogestão como resposta ao desemprego. São Paulo, Editora Contexto, 2000.

GOMES, A.J. Origem e evolução do cooperativismo no mercado e no Brasil e sua contribuição para constituir o segmento educacional brasileiro. Linguagens, educação e sociedade: revista do Programa de Pós-graduação em Educação da UFPI, Teresina, n.12,2005.

ORTIZ, R. H. Economia Solidária. Hacia uma nueva civilización. Lima, 2001.

PINHEIRO, Daniel Calbino. Economia Solidária: Uma Revisão Teórica a Partir dos Seus “Múltiplos" Conceitos. Revista NAU Social, v. 3, n. 5, p. 85-105, 2013. Disponível em: http://base.socioeco.org/docs/_index106.pdf. Acesso: 30 ago 2018.

PLANO ESTADUAL DE ECONOMIA SOLIDÁRIA. Para promover o direito de produzir e viver de forma associativa e sustentável. 2017.

PRAXEDES, Sandra Faé. Políticas públicas de Economia Solidária: novas práticas, novas metodologias. 2009. IN: Édi Benini ...[et al] (organizadores). Gestão pública e sociedade: fundamentos e políticas públicas de economia solidária. 1.ed. São Paulo: Outras Expressões,2012.

SINGER, Paul. A Economia Solidária no Governo Federal. Revista Mercado de Trabalho. Ipea. Rio de Janeiro, 24 de agosto de 2004. IN: Édi Benini ...[et al] (organizadores). Gestão pública e sociedade: fundamentos e políticas públicas de economia solidária. 1.ed. São Paulo: Outras Expressões, 2011.

SINGER, Paul. Introdução a Economia Solidária / Paul Singer - 1a ed - São Paulo Editora Fundação Perseu Abramo, 2002.

SCHICHET, Valmor. Da Democracia à autogestão: Economia Solidária no Brasil. In: BENINI, Edi, A.et all. (orgs). Gestão Pública e Sociedade: fundamentos e políticas públicas de Economia Solidária. São Paulo: Outras Expressões, vol. II, 2012.

SISTEMAS DE INFORMAÇÕES TERRITORIAS - SIT disponível online via http://sit.mda.gov.br/download/ptdrs/ptdrs_qua_territorio059.pdf, 2019. Data de consulta: 001/06/2019. 